\title{
RESEARCH
}

Open Access

\section{Incidence of neonatal mortality and its predictors among live births in Ethiopia: Gompertz gamma shared frailty model}

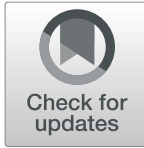

Zemenu Tadesse Tessema* and Getayeneh Antehunegn Tesema

\begin{abstract}
Background: Neonatal mortality remains a serious public health concern in developing countries including Ethiopia. Ethiopia is one of the countries with the highest neonatal mortality in Africa. However, there is limited evidence on the incidence and predictors of neonatal mortality at the national level. Therefore, this study aimed to investigate the incidence of neonatal mortality and its predictors among live births in Ethiopia. Investigating the incidence and predictors of neonatal mortality is essential to design targeted public health interventions to reduce neonatal mortality.
\end{abstract}

Methods: A secondary data analysis was conducted based on the 2016 Ethiopian Demographic and Health Survey (EDHS) data. A total weighted sample of 11,022 live births was included in the analysis. The shared frailty model was applied since the EDHS data has hierarchical nature, and neonates are nested within-cluster, and this could violate the independent and equal variance assumption. For checking the proportional hazard assumption, Schoenfeld residual test was applied. Akakie Information Criteria (AIC), Cox-Snell residual test, and deviance were used for checking model adequacy and for model comparison. Gompertz gamma shared frailty model was the best-fitted model for this data since it had the lowest deviance, AIC value, and the Cox-Snell residual graph closet to the bisector. Variables with a $p$-value of less than 0.2 were considered for the multivariable Gompertz gamma shared frailty model. In the multivariable Gompertez gamma shared frailty model, the Adjusted Hazard Ratio (AHR) with a 95\% confidence interval (Cl) was reported to identify significant predictors of neonatal mortality.

Results: Overall, the neonatal mortality rate in Ethiopia was 29.1 (95\% Cl: 26.1, 32.4) per 1000 live births. In the multivariable Gompertz gamma shared frailty model; male sex ( $\mathrm{AHR}=1.92,95 \% \mathrm{Cl}: 1.52,2.43)$, twin birth ( $\mathrm{AHR}=$ 5.22, 95\% Cl: 3.62, 7.53), preceding birth interval less than 18 months (AHR $=2.07,95 \% \mathrm{Cl}: 1.51,2.85$ ), small size at birth $(A H R=1.64,95 \% \mathrm{Cl}: 1.24,2.16)$, large size at birth $(\mathrm{AHR}=1.53,95 \% \mathrm{Cl}: 1.16,2.01)$ and did not have Antenatal Care (ANC) visit (AHR $=2.10,95 \% \mathrm{Cl}: 1.44,3.06)$ were the significant predictors of neonatal mortality.

(Continued on next page)

\footnotetext{
* Correspondence: getayenehantehunegn@gmail.com

Department of Epidemiology and Biostatistics, Institute of Public Health, College of Medicine and Health Sciences, University of Gondar, Gondar, Ethiopia
}

(c) The Author(s). 2020 Open Access This article is licensed under a Creative Commons Attribution 4.0 International License, which permits use, sharing, adaptation, distribution and reproduction in any medium or format, as long as you give appropriate credit to the original author(s) and the source, provide a link to the Creative Commons licence, and indicate if changes were made. The images or other third party material in this article are included in the article's Creative Commons licence, unless indicated otherwise in a credit line to the material. If material is not included in the article's Creative Commons licence and your intended use is not permitted by statutory regulation or exceeds the permitted use, you will need to obtain permission directly from the copyright holder. To view a copy of this licence, visit http://creativecommons.org/licenses/by/4.0/ The Creative Commons Public Domain Dedication waiver (http://creativecommons.org/publicdomain/zero/1.0/) applies to the data made available in this article, unless otherwise stated in a credit line to the data. 


\begin{abstract}
(Continued from previous page)
Conclusion: Our study found that neonatal mortality remains a public health problem in Ethiopia. Shorter birth interval, small and large size at birth, ANC visits, male sex, and twin births were significant predictors of neonatal mortality. These results suggest that public health programs that increase antenatal care service utilization should be designed to reduce neonatal mortality and special attention should be given for twin births, large and low birth weight babies. Besides, providing family planning services for mothers to increase birth intervals and improving accessibility and utilization of maternal health care services such as ANC is crucial to improve neonatal survival.
\end{abstract}

Keywords: Ethiopia, Gompertz gamma shared frailty, Neonatal mortality

\section{Background}

According to the World Health Organization (WHO), neonatal mortality is defined as the death of babies within 28 days of birth [1] and is considered as the most sensitive indicators of the socioeconomic status of the community, and health care service availability and accessibility of the country [2,3]. Globally, 2.5 million newborn babies died annually, of which $99 \%$ occurred in developing countries [4]. Neonatal mortality constitutes $40 \%$ of total under- 5 mortality and $57 \%$ of global infant mortality [5]. Reducing neonatal mortality is an integral component of Goal 3 of Sustainable Development Goal (SDG) to end preventable death [6]. Globally, neonatal mortality is an unresolved Millennium Development Goals (MDG4) agenda and remains unacceptably high, with 7000 deaths a day [7].

Neonatal mortality has decreased steadily over the past two decades, although this was the slowest in Sub-Saharan Africa (SSA), where $38 \%$ of global neonatal mortality occurred [8]. Ethiopia has among African countries with the highest newborn mortality rates $[9,10]$. The Neonatal Mortality Rate (NMR) in Ethiopia has decreased in the last 16 years, from 49 to 29 per 1000 live births. Still, it is far below the United Nations' (UN) ambitious target of preventing preventable newborn deaths and reducing neonatal mortality to 12 per 1000 live births in every country by 2030 [11]. The majority of neonatal death are caused by preventable and treatable causes such as diarrheal disease, pneumonia, sepsis, asphyxia, and prematurity that can be avoided by using basic maternal and child health care services [12-14].

While Ethiopia has made large-scale investments and programs such as the implementation of the Health Extension Program (HEP), quality and accessibility of maternal healthcare services, and Millennium Development Goals, it is among the few countries with the highest NMR burden $[15,16]$. Previous studies documented on neonatal mortality found that maternal age [17], residence [18], birth interval [19], birth weight [20], place of delivery [21], birth order [22], husband education [23], Antenatal Care (ANC) visit [24, 25], media exposure [25], Postnatal Care (PNC) visit [26], multiple gestation [27], and maternal education [28] were significant predictors of neonatal mortality.
According to the EDHS reports, the neonatal mortality rate decreased from 49 per 1000 births in 2000 [29] to 29 per 1000 live births in 2016 [30], which accounts for $43.3 \%$ of deaths under 5 in Ethiopia [31]. However, there is limited evidence on the incidence and predictors of neonatal mortality at the national level using survival analysis. Understanding the incidence and predictors of neonatal mortality is critical to design effective public health programs and interventions to reduce neonatal mortality in Ethiopia. Therefore, this study aimed to investigate the incidence of and predictors of neonatal mortality in Ethiopia.

\section{Methods}

\section{Data source}

A secondary data analysis was conducted based on the EDHS 2016 data. The 2016 EDHS survey was the fourth survey conducted in Ethiopia, situated in the Horn of Africa. Ethiopia has 9 regional states (Afar, Amhara, Benishangul-Gumuz, Gambela, Harari, Oromia, Somali, Southern Nations, Nationalities, and People's Region (SNNPR) and Tigray) and two Administrative Cities (Addis Ababa and Dire-Dawa). The EDHS used a stratified two-stage cluster sampling technique selected in two stages using the 2007 Population and Housing Census (PHC) as a sampling frame. Stratification was achieved by separating each region into urban and rural areas. In total, 21 sampling strata have been created. In the first stage, 645 Enumeration Areas (EAs) (202 in the urban area) were selected with probability selection proportional to the EA size and independent selection in each sampling stratum. In the second stage, on average, 28 households were systematically selected. A total weighted sample of 11,022 live births within 5 years preceding the survey were included. The detailed sampling procedure was presented in the full EDHS 2016 report [32].

\section{Study variables}

The outcome variable for this study was neonatal survival status categorized as being alive (coded as 0) or died (coded as 1). Neonatal mortality is defined as the death of live birth within 28 days of life. Age at death was recorded in days if the child died within 28 days of 
delivery. The independent variables considered for this study were categorized as socio-demographic and economic variables (residence, region, religion, maternal education, husband education, maternal occupation, sex of household head, distance to the health facility and wealth status), child-related factors (sex of neonate, type of birth, preceding birth interval and birth size), and maternal healthcare services related factors (ANC visit, place of delivery, mode of delivery, parity, birth order, wanted pregnancy, and health insurance coverage).

\section{Data management and analysis}

The data were weighted using sampling weight, primary sampling unit, and strata before any statistical analysis to restore the representativeness of the survey and take into account the sampling design to get reliable statistical estimates. The sampling statisticians determine how many samples are needed in each stratum to get reliable estimates, in EDHS, some regions were oversampled, and some regions were under-sampled. So, to get statistics that are representative of Ethiopia, the distribution of neonate in the sample need to be weighted (mathematically adjusted) such that it resembles the true distribution in Ethiopia by using sampling weight (v005), primary sampling unit (v021) and strata (v022). The descriptive and summary statistics were conducted using STATA version 14 software. The EDHS data has a hierarchical structure, and therefore neonates are nested within a cluster/EAs. This violates the traditional regression model assumption, which is the independence of observations and equal variance across clusters. We have checked whether there was clustering or not by running the frailty model (random effect survival model). EA was used as a random effect (clustering variable). The theta parameter was used to assess whether there is significant clustering or not. The EDHS data were collected at twolevel at individual and at the community level. Therefore, neonates in the same cluster are more of share similar characteristics than neonates in another cluster. The theta (frailty parameter) was significant at the null model $(\theta=0.45,95 \% \mathrm{CI}: 0.22,0.83)$. It showed that there was unobserved heterogeneity or shared frailty that needs to be taken into account to get a reliable estimate. Schoenfeld residual test was applied to check the Proportional Hazard $(\mathrm{PH})$ assumptions, and the $\mathrm{PH}$ assumption was fulfilled ( $p$-value>0.05). For model selection, log-likelihood ratio test, deviance (-2LL), Akaike Information Criteria (AIC), and Cox-Snell residual plot were applied. Cox-Snell Residual test is the difference between an observed data point and a predicted or fitted value. A Cox-Snell residual considers the distribution and estimated parameters from the lifetime regression model. A model with the highest values of log-likelihood and the lowest value of AIC was the best- fitted model. Nested parametric models in generalized gamma (Exponential, Weibull, lognormal) were compared based on deviance, and non-nested models (Gompertz and log-logistic) were compared using AIC. Deviance, AIC, and Cox-Snell residual graph showed that the Gompertz gamma shared frailty model had the lowest value and the closet graph to the bisector. Therefore, the Gompertz gamma shared frailty model was the best-fitted model for the data.

Variable with a $p$-value less 0.20 in the uni-variable gamma shared frailty analysis were included in the multivariable analysis. We estimate the hazard ratio and 95\% confidence interval. In the multivariable analysis, the Adjusted Hazard Ratio (AHR) with 95\% Confidence Interval (CI) was used to declare significant predictors of neonatal mortality.

\section{Ethical consideration}

Permission for data access was obtained from major demographic and health survey through an online request from http://www.dhsprogram.com. The data used for this study were publicly available with no personal identifier.

\section{Result}

\section{Characteristics of the study population}

A total of 11,022 live births were included in this study, of these, 5725 (51.9\%) were males, and 292 (2.6\%) were twin births. More than two-thirds (72.6\%) of the births were delivered at home, and $89 \%$ were born to mothers lived in rural areas. About 5842 (53.0\%) of the births were born to mothers aged 25-34 years, and 7284 (66.1\%) were born to mothers who had no formal education. Three-fourth $(75.1 \%)$ of the births were wanted, and 4836 (43.9\%) were born to mothers who had 2-4 births (Table 1).

\section{Neonatal mortality rate by respondents characteristics}

From a total of 11,022 live births, 321 babies died within 28 days of birth. The overall neonatal mortality rate in Ethiopia was 29.1 [95\% CI: 26.1, 32.4] per 1000 live births. The neonatal mortality rate has been varied across regions, ranged from 20.7 per 1000 live births in Addis Ababa to 40.8 per 1000 live births in the Somali region. Of the total 251 twin births, 14.1\% died during the neonatal period. The neonatal mortality rate was highest among male children, mothers who had no ANC visit during pregnancy, shorter preceding birth intervals, and small birth sizes (Table 2).

\section{Predictors of neonatal mortality}

Based on deviance, AIC, Cox-Snell residual test, and theta value, the shared frailty model with Gompertz distribution and gamma frailty was the most efficient model 
Table 1 Characteristics of the study population in Ethiopia, 2016

\begin{tabular}{|c|c|c|}
\hline Characteristics & Category & $\begin{array}{l}\text { Weighted } \\
\text { frequency (\%) }\end{array}$ \\
\hline \multirow[t]{2}{*}{ Residence } & Rural & $9807(89.0)$ \\
\hline & Urban & $1215(11.0)$ \\
\hline \multirow[t]{11}{*}{ Region } & Tigray & $716(6.5)$ \\
\hline & Afar & $114(1.0)$ \\
\hline & Amhara & $2072(18.8)$ \\
\hline & Oromia & $4851(44.0)$ \\
\hline & Somali & $508(4.6)$ \\
\hline & Benishangul-Gumuz & $121(1.1)$ \\
\hline & SNNPRS & $2296(20.8)$ \\
\hline & Gambella & $27(0.2)$ \\
\hline & Harari & $26(0.2)$ \\
\hline & Addis Ababa & $243(2.2)$ \\
\hline & Dire Dawa & $47(0.4)$ \\
\hline \multirow[t]{3}{*}{ Maternal age } & $15-24$ & $2446(22.2)$ \\
\hline & $25-34$ & $5842(53.0)$ \\
\hline & $\geq 35$ & $2734(24.8)$ \\
\hline \multirow[t]{5}{*}{ Wealth index } & Poorest & $2636(23.9)$ \\
\hline & Poorer & $2520(22.9)$ \\
\hline & Middle & $2280(20.7)$ \\
\hline & Richer & $1998(18.1)$ \\
\hline & Richest & $1588(14.4)$ \\
\hline \multirow[t]{3}{*}{ Maternal education status } & No & $7284(66.1)$ \\
\hline & Primary & $2950(26.8)$ \\
\hline & $\begin{array}{l}\text { Secondary and } \\
\text { above }\end{array}$ & $788(7.1)$ \\
\hline \multirow[t]{3}{*}{ Husband education status } & No & $5003(45.4)$ \\
\hline & Primary & $4112(37.3)$ \\
\hline & $\begin{array}{l}\text { Secondary and } \\
\text { above }\end{array}$ & $1904(17.3)$ \\
\hline \multirow[t]{2}{*}{ Maternal occupation } & Not working & $8034(72.9)$ \\
\hline & Working & $2988(27.1)$ \\
\hline \multirow[t]{2}{*}{ Child was wanted } & No & $2743(24.9)$ \\
\hline & Yes & $8279(75.1)$ \\
\hline \multirow[t]{2}{*}{ Sex of child } & Male & $5725(51.9)$ \\
\hline & Female & $5297(48.1)$ \\
\hline \multirow[t]{2}{*}{ Type of birth } & Single & $10,730(97.4)$ \\
\hline & Twin & $292(2.6)$ \\
\hline \multirow[t]{2}{*}{ Place of delivery } & Home & 7997 (72.6) \\
\hline & Health facility & 3025 (27.4) \\
\hline \multirow{3}{*}{$\begin{array}{l}\text { Preceding birth interval (in } \\
\text { months) }\end{array}$} & $<18$ & $942(8.6)$ \\
\hline & $18-36$ & 4112 (37.3) \\
\hline & $\geq 37$ & $5968(54.1)$ \\
\hline Birth size & Small & $2957(26.8)$ \\
\hline
\end{tabular}

Table 1 Characteristics of the study population in Ethiopia, 2016 (Continued)

\begin{tabular}{lll}
\hline Characteristics & Category & $\begin{array}{l}\text { Weighted } \\
\text { frequency (\%) }\end{array}$ \\
\hline \multirow{3}{*}{ Sex of household head } & Average & $4580(41.6)$ \\
& Large & $3485(31.6)$ \\
ANC visit & Female & $1529(13.9)$ \\
& Male & $9493(86.1)$ \\
Parity & No & $6266(56.9)$ \\
& Yes & $4756(43.1)$ \\
& 1 & $1434(13.0)$ \\
Media exposure & $2-4$ & $4836(43.9)$ \\
& $\geq 5$ & $4752(43.1)$ \\
Covered by health insurance & No & $7375(66.9)$ \\
& No & $3647(33.1)$ \\
& yes & $10,633(94.5)$ \\
\hline
\end{tabular}

for the data (Table 3, and Fig. 1). The goodness of fit for the fitted model was also performed using the Cox-Snell residual test and showed that the model was adequate.

In the Gompertz gamma shared frailty model; residence, maternal age, maternal education, wealth index, sex of household head, sex of neonate, type of birth, parity, preceding birth interval, birth size, media exposure, covered by health insurance, TT vaccination status and wanted birth were considered for multivariable analysis since they head $p$-value $<0.2$ in the bi-variable analysis. However, in the multivariable analysis, sex of neonate, ANC visit, type of birth, preceding birth interval, and birth size were significant predictors of neonatal mortality.

The hazard of neonatal death among male births was $1.92(\mathrm{AHR}=1.92,95 \% \mathrm{CI}: 1.52,2.43)$ times higher than females. The hazard of neonatal death among twin births was $5.22(\mathrm{AHR}=5.22,95 \% \mathrm{CI}: 3.62,7.53)$ times higher than single births. Live births who were born within the preceding birth interval of fewer than 18 months was $2.07(\mathrm{AHR}=2.07,95 \%$ CI: 1.51, 2.85) times more at risk of death in the neonatal period compared to live births who had a preceding birth interval of 18-36 months. Children born to mothers who didn't have ANC visits during pregnancy had 2.10 ( $\mathrm{AHR}=2.10,95 \% \mathrm{CI}: 1.44$, 3.06) times higher risk of death during the neonatal period compared to children born to mother who had ANC visit. Those live births who were small size at birth and large size at birth was $1.64(\mathrm{AHR}=1.64,95 \% \mathrm{CI}$ : $1.24,2.16)$ and $1.53(\mathrm{AHR}=1.53,95 \% \mathrm{CI}: 1.16,2.01)$ times increased risk of death in the neonatal period compared to live births who were average size at birth (Table 4). 
Table 2 Neonatal mortality rates by respondents characteristics in Ethiopia, 2016

\begin{tabular}{|c|c|c|c|c|}
\hline \multirow[t]{2}{*}{ Characteristics } & \multirow[t]{2}{*}{ Category } & \multicolumn{2}{|l|}{ Status } & \multirow{2}{*}{$\begin{array}{l}\text { NMR } \\
\text { per } \\
1000 \\
\text { live } \\
\text { births }\end{array}$} \\
\hline & & Event & Censured & \\
\hline \multirow[t]{2}{*}{ Residence } & Rural & 9527 & 280 & 28 \\
\hline & Urban & 1174 & 41 & 34 \\
\hline \multirow[t]{11}{*}{ Region } & Tigray & 696 & 19 & 26.9 \\
\hline & Afar & 111 & 3 & 26.2 \\
\hline & Amhara & 2006 & 66 & 32.1 \\
\hline & Oromia & 4711 & 139 & 28.8 \\
\hline & Somali & 487 & 21 & 40.8 \\
\hline & Benishangul-Gumuz & 118 & 4 & 28.7 \\
\hline & SNNPRS & 2236 & 60 & 26.2 \\
\hline & Gambella & 26 & 1 & 28.0 \\
\hline & Harari & 25 & 1 & 31.3 \\
\hline & Addis Ababa & 239 & 5 & 20.7 \\
\hline & Dire Dawa & 45 & 1 & 29.8 \\
\hline \multirow[t]{3}{*}{ Maternal age } & $15-24$ & 2387 & 59 & 24.0 \\
\hline & $25-34$ & 5687 & 155 & 26.6 \\
\hline & $\geq 35$ & 2628 & 106 & 38.9 \\
\hline \multirow[t]{5}{*}{ Wealth index } & Poorest & 2584 & 52 & 19.7 \\
\hline & Poorer & 2446 & 73 & 29.1 \\
\hline & Middle & 2209 & 70 & 30.8 \\
\hline & Richer & 1921 & 77 & 38.9 \\
\hline & Richest & 1540 & 47 & 30.0 \\
\hline \multirow[t]{3}{*}{ Maternal education status } & No & 7058 & 225 & 30.9 \\
\hline & Primary & 2880 & 71 & 24.0 \\
\hline & Secondary and above & 763 & 25 & 31.4 \\
\hline \multirow[t]{3}{*}{ Husband education status } & No & 4850 & 152 & 30.5 \\
\hline & Primary & 3998 & 118 & 28.7 \\
\hline & Secondary and above & 1854 & 50 & 26.4 \\
\hline \multirow[t]{2}{*}{ Maternal occupation } & Not working & 7798 & 236 & 29.4 \\
\hline & Working & 2903 & 85 & 28.4 \\
\hline \multirow[t]{2}{*}{ Child was wanted } & No & 2660 & 83 & 30.3 \\
\hline & Yes & 8042 & 238 & 28.7 \\
\hline \multirow[t]{2}{*}{ Sex of child } & Male & 5496 & 229 & 40.0 \\
\hline & Female & 5206 & 92 & 17.4 \\
\hline \multirow[t]{2}{*}{ Type of birth } & Single & 10,450 & 280 & 26.1 \\
\hline & Twin & 251 & 41 & 141.0 \\
\hline \multirow[t]{2}{*}{ Place of delivery } & Home & 7780 & 217 & 27.1 \\
\hline & Health facility & 2921 & 104 & 34.3 \\
\hline \multirow[t]{3}{*}{ Preceding birth interval (in months) } & $<18$ & 888 & 54 & 57.7 \\
\hline & $18-36$ & 4001 & 110 & 26.9 \\
\hline & $\geq 37$ & 5812 & 156 & 26.1 \\
\hline Birth size & Small & 3362 & 122 & 35.1 \\
\hline
\end{tabular}


Table 2 Neonatal mortality rates by respondents characteristics in Ethiopia, 2016 (Continued)

\begin{tabular}{|c|c|c|c|c|}
\hline \multirow[t]{2}{*}{ Characteristics } & \multirow[t]{2}{*}{ Category } & \multicolumn{2}{|l|}{ Status } & \multirow{2}{*}{$\begin{array}{l}\text { NMR } \\
\text { per } \\
1000 \\
\text { live } \\
\text { births }\end{array}$} \\
\hline & & Event & Censured & \\
\hline & Average & 4483 & 97 & 21.2 \\
\hline & Large & 2856 & 101 & 34.2 \\
\hline \multirow[t]{2}{*}{ Sex of household head } & Female & 1490 & 38 & 25.1 \\
\hline & Male & 9211 & 282 & 29.7 \\
\hline \multirow[t]{2}{*}{ ANC visit } & No & 6028 & 238 & 37.9 \\
\hline & Yes & 4673 & 83 & 17.5 \\
\hline \multirow[t]{3}{*}{ Parity } & 1 & 1422 & 12 & 8.9 \\
\hline & $2-4$ & 4684 & 151 & 31.4 \\
\hline & $\geq 5$ & 4596 & 156 & 32.9 \\
\hline \multirow[t]{2}{*}{ Media exposure } & No & 7192 & 183 & 24.8 \\
\hline & Yes & 3510 & 138 & 37.7 \\
\hline
\end{tabular}

\section{Discussion}

The overall aim of this study was to investigate the incidence of neonatal mortality and its predictors in Ethiopia based on weighted nationally representative EDHS 2016 data using the Gompertz gamma shared frailty model. In this study, the neonatal mortality rate in Ethiopia was 29.1 (95\% CI: 26.1, 32.4) per 1000 live births with an Annual Rate of Reduction (ARR) of $2.6 \%$. This was lower than a study reported in Nigeria [33], the possible justification could be due to the difference in the study period and the difference in the study population. Besides, it could be due to the continued commitment of Ethiopia to improve maternal and newborn survival by implementation continued investment in accessing basic health care services. But this finding was higher than the United Nations Every New Born action plan [34]. This provides an insight that Ethiopia should reduce neonatal mortality to reach every born action plan by 2030 .

In the Gompertz gamma shared frailty analysis; type of birth, preceding birth interval, birth size, sex of neonate, and ANC visit during pregnancy were significant predictors of neonatal mortality. In the current study, the hazard of neonatal mortality was higher among twin births than singletons. It was in line with a study reported in Ghana [35]. This might be due to the increased risk of twins to prematurity, low birth weight, Intra-Uterine Growth Restriction (IUGR), twin to twin transfusion syndrome, and congenital anomaly that increases the risk of dying during the neonatal period than singletons $[36,37]$. Besides, twins are more prone to malnutrition compared to singletons, thus they are prone to infectious diseases, hypothermia, and sepsis [38] this could increase their risk of mortality during the neonatal period.

The hazard of neonatal mortality was higher among male births was than female births. This was consistent with study findings in Ethiopia [39], Sudan [40], and Pakistan [41]. The possible justification could be due to the preconception environment, thus biologically male children are at higher risk of infectious diseases due to higher prevalence of immune-deficiency, and have delayed fetal lung maturity, this could result in male

Table 3 Model diagnostics and comparison

\begin{tabular}{|c|c|c|c|c|c|c|}
\hline Model & Distribution & Frailty & Theta & AIC & BIC & Deviance (-2LL) \\
\hline Cox proportion hazard & Unspecified & Unspecified & - & 5802 & 5969 & 5756 \\
\hline Shared frailty & Gompertz & Gamma & 0.39 & 3757 & 3946 & 3704 \\
\hline Shared frailty & Gompertz & Inverse Gaussian & 0.44 & 3757 & 3946 & 3704 \\
\hline Shared frailty & Exponential & Gamma & 0.51 & 4211 & 4393 & 4160 \\
\hline Shared frailty & Exponential & Inverse Gaussian & 0.59 & 4210 & 4392 & 3850 \\
\hline Shared frailty & Weibull & gamma & 0.40 & 3902 & 4091 & 3850 \\
\hline Shared frailty & Weibull & Inverse Gaussian & 0.60 & 3902 & 4091 & 3850 \\
\hline Shared frailty & Log-normal & gamma & 0.40 & 3878 & 4067 & 3826 \\
\hline Shared frailty & Log-normal & Inverse Gaussian & 0.45 & 3910 & 4012 & 3932 \\
\hline
\end{tabular}




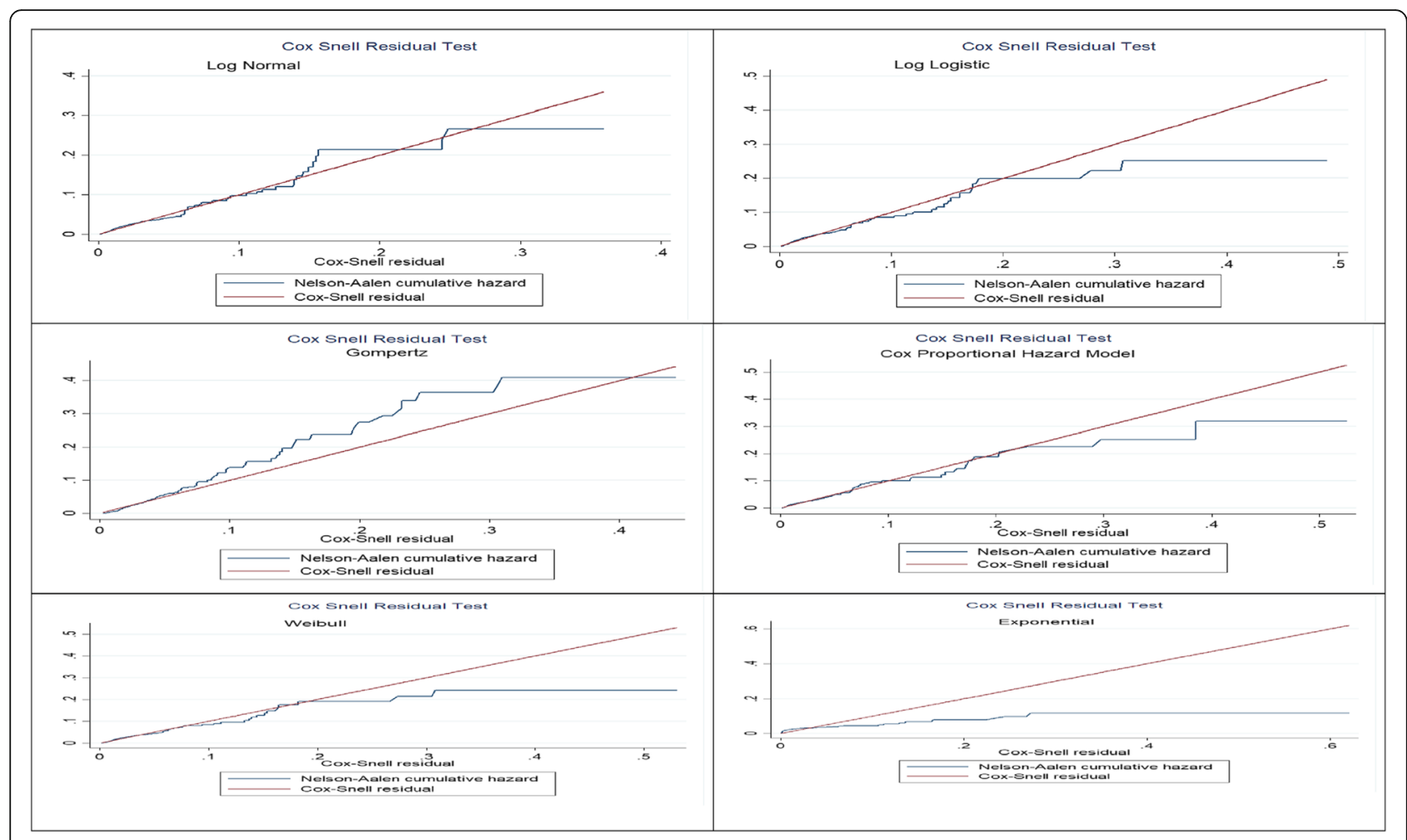

Fig. 1 The Cox-Snell Residual test of semi parametric and parametric survival models

neonates at higher risk of respiratory diseases and high risk of mortality [42, 43].

The preceding birth interval was a significant predictor of neonatal mortality. Having the preceding birth interval of fewer than 18 months increases neonatal mortality risk than births with preceding birth interval of 18-36 months. This is supported by previous study findings in Indonesia [19], and Nigeria [44]. The possible explanation could be due to the reason that mothers having shorter preceding birth intervals are less able to provide nourishment for the fetus because her body has less time to recuperate from the previous pregnancy. Besides, the uterus had less time to recover, and also lactation will deplete maternal nutrition [45] this could result in low birth weight, preterm labor, etc. due to lack of care, attention, and competition of children that could increase the risk of neonatal mortality.

Live births born to women who didn't have ANC visits during pregnancy were at higher risk of death in the neonatal period than live births born to mothers who had ANC visits during pregnancy. This was consistent with study findings in Kenya [24] and Bangladesh [25]. The possible justification might be due to the reason that ANC offers pregnant women an opportunity to access preventive care, treatment, and health education, including child nutritional advice and seeking treatment [46]. Also, ANC is considered an entry point for other maternal healthcare service utilization. Women who have ANC visit are advised to seek skilled delivery and PNC visit as well as they have a good awareness about childhood illness and seeking medical care [47].

Mothers who perceived the size of their newborns were small and large size at birth had a higher risk of death in the first month of life compared to newborns who were average-sized at birth. It was consistent with a study in Bangladesh [48]. This could be because the small size and large size babies are indicators of underlying congenital abnormality including neural tube defect, congenital heart diseases, and Down syndrome and/ or medical illness of the new-borns including congenital syphilis, tuberculosis, HIV cytomegalovirus, malaria, sepsis, etc. furthermore, small size babies are more prone to hypothermia, and infection, this could lead to the death of the neonate [49].

The strength of this study was, it was based on the weighted data to make it representativeness at national and regional levels. Therefore, it can be generalized to all live births during the study period in Ethiopia. Moreover, the use of shared frailty modeling that took into account the nested nature of the EDHS data and the variability within the community to get a reliable estimate and standard errors. This study had limitations. First, in EDHS, only surviving women were interviewed, and this could underestimate the neonatal mortality rate 
Table 4 Shared Gompertz distribution gamma shared frailty model for the predictors of neonatal mortality in Ethiopia, 2016

\begin{tabular}{|c|c|c|c|c|}
\hline \multirow[t]{2}{*}{ Variable } & \multicolumn{2}{|c|}{ Neonate died } & \multirow{2}{*}{$\begin{array}{l}\text { Crude Hazard } \\
\text { Ratio (CHR) } \\
\text { with } 95 \% \mathrm{Cl}\end{array}$} & \multirow{2}{*}{$\begin{array}{l}\text { Adjusted } \\
\text { Hazard Ratio } \\
\text { (AHR) with 95\% Cl }\end{array}$} \\
\hline & No & Yes & & \\
\hline \multicolumn{5}{|l|}{ Residence } \\
\hline Urban & 1175 & 41 & 1 & 1 \\
\hline Rural & 9527 & 279 & $1.83[1.27,2.64]$ & $1.51[0.86,2.64]$ \\
\hline \multicolumn{5}{|l|}{ Maternal age } \\
\hline $15-24$ & 2387 & 59 & $0.85[0.64,1.15]$ & $0.93[0.62,1.39]$ \\
\hline $25-34$ & 5687 & 155 & $0.66[0.50,0.85]$ & $0.64[0.48,0.87]$ \\
\hline$\geq 35$ & 2628 & 106 & 1 & 1 \\
\hline \multicolumn{5}{|c|}{ Maternal education status } \\
\hline No & 7058 & 225 & 1 & 1 \\
\hline Primary & 2880 & 71 & $0.87[0.66,1.14]$ & $1.13[0.84,1.52]$ \\
\hline Secondary and higher & 763 & 24 & $0.77[0.51,1.15]$ & $1.36[0.83,2.24]$ \\
\hline \multicolumn{5}{|l|}{ Wealth status } \\
\hline Poorest & 2584 & 52 & $1.73[1.20,2.50]$ & $0.92[0.52,1.63]$ \\
\hline Poorer & 2446 & 73 & $1.78[1.18,2.68]$ & $1.09[0.60,1.96]$ \\
\hline Middle & 2209 & 70 & $1.56[1.01,2.42]$ & $0.99[0.54,1.88]$ \\
\hline Richer & 1921 & 78 & $1.49[0.95,2.33]$ & $0.95[0.53,1.71]$ \\
\hline Richest & 1540 & 47 & 1 & 1 \\
\hline \multicolumn{5}{|l|}{ Sex of household } \\
\hline Male & 9211 & 282 & 1 & 1 \\
\hline Female & 1491 & 38 & $0.65[0.48,0.89]$ & $0.68[0.49,1.02]$ \\
\hline \multicolumn{5}{|l|}{ Sex of neonate } \\
\hline Female & 5206 & 92 & 1 & 1 \\
\hline Male & 5496 & 228 & $1.87[1.49,2.37]$ & $1.92[1.52,2.43]^{*}$ \\
\hline \multicolumn{5}{|l|}{ Type of birth } \\
\hline Single & 10,451 & 279 & 1 & 1 \\
\hline Twin & 251 & 41 & $6.12[4.31,8.69]$ & $5.22[3.62,7.53]^{*}$ \\
\hline \multicolumn{5}{|l|}{ Parity } \\
\hline 1 & 1421 & 13 & 1 & 1 \\
\hline $2-4$ & 4684 & 151 & $1.73[1.14,2.63]$ & $1.23[0.77,1.97]$ \\
\hline$\geq 5$ & 4596 & 156 & $1.96[1.29,2.99]$ & $1.10[0.63,1.93]$ \\
\hline \multicolumn{5}{|l|}{ Preceding birth interval } \\
\hline $18-36$ months & 4001 & 110 & 1 & 1 \\
\hline$<18$ months & 888 & 54 & $2.10[1.53,2.88]$ & $2.07[1.51,2.85]^{*}$ \\
\hline$>36$ months & 5813 & 156 & $0.95[0.75,1.22]$ & $1.05[0.81,1.38]$ \\
\hline \multicolumn{5}{|l|}{ Size of neonate at birth } \\
\hline Average & 4483 & 97 & 1 & 1 \\
\hline Small & 2856 & 101 & $1.67[1.27,2.19]$ & $1.64[1.24,2.16]^{*}$ \\
\hline Large & 3362 & 122 & $1.51[1.15,1.99]$ & $1.53[1.16,2.01]^{*}$ \\
\hline \multicolumn{5}{|l|}{ Media exposure } \\
\hline No & 7192 & 183 & 1 & 1 \\
\hline Yes & 3510 & 137 & $0.88[0.69,1.13]$ & $1.14[0.85,1.53]$ \\
\hline \multicolumn{5}{|c|}{ Covered by health insurance } \\
\hline No & 10,321 & 311 & 1 & 1 \\
\hline
\end{tabular}


Table 4 Shared Gompertz distribution gamma shared frailty model for the predictors of neonatal mortality in Ethiopia, 2016 (Continued)

\begin{tabular}{|c|c|c|c|c|}
\hline \multirow[t]{2}{*}{ Variable } & \multicolumn{2}{|c|}{ Neonate died } & \multirow{2}{*}{$\begin{array}{l}\text { Crude Hazard } \\
\text { Ratio (CHR) } \\
\text { with } 95 \% \mathrm{Cl}\end{array}$} & \multirow{2}{*}{$\begin{array}{l}\text { Adjusted } \\
\text { Hazard Ratio } \\
\text { (AHR) with } 95 \% \mathrm{Cl}\end{array}$} \\
\hline & No & Yes & & \\
\hline Yes & 380 & 9 & $0.52[0.21,1.28]$ & $0.64[0.26,1.59]$ \\
\hline \multicolumn{5}{|c|}{ ANC visit during pregnancy } \\
\hline No & 6028 & 238 & 1 & 1 \\
\hline Yes & 4673 & 83 & $2.95[2.25,3.86]$ & $2.10[1.44,3.06]$ \\
\hline \multicolumn{5}{|c|}{ Vaccinated for $\pi$ during pregnancy } \\
\hline No & 6762 & 249 & $2.67[2.00,3.57]$ & $1.41[0.95,2.10]$ \\
\hline Yes & 3940 & 71 & 1 & 1 \\
\hline \multicolumn{5}{|c|}{ Wanted child } \\
\hline Yes & 8041 & 237 & 1 & 1 \\
\hline No & 2660 & 83 & $0.80[0.59,1.10]$ & $0.79[0.57,1.09]$ \\
\hline
\end{tabular}

* $=p$-value $<0.01$

since maternal mortality is commonly associated with neonatal mortality. Furthermore, the EDHS survey did not incorporate clinically confirmed data; instead, it relied on mothers or caregivers report and might have the possibility of social desirability and recall bias, and variables like maternal obstetric complications such as Antepartum Hemorrhage (APH), preeclampsia, eclampsia, Premature Rupture of Membrane (PROM), infection, and congenital anomalies which may be considered as the most common cause of neonatal mortality were not addressed in this study because these variables were not available in EDHS data.

\section{Conclusions}

The neonatal mortality rate in Ethiopia remains a major public health problem. Male sex, twin birth, shorter preceding birth interval, having no ANC visit, and small and large size at birth were significantly associated with increased risk of neonatal mortality. Therefore, to reduce neonatal mortality, integrated public health interventions are needed. Giving special medical care and follow up for twin births, small and large babies, and male births are mandatory to reduce the incidence of neonatal mortality. Providing family planning services for mothers to increase birth intervals and improving accessibility and utilization of maternal health care services such as ANC is crucial to improve neonatal survival.

\footnotetext{
Abbreviations

AHR: Adjusted Hazard Ratio; AIC: Akaike Information Criteria; ANC: Antenatal Care; BIC: Bayesian Information Criteria; Cl: Confidence Interval; CHR: Crude Hazard Ratio; EAs: Enumeration Areas; EDHS: Ethiopian Demographic and Health Survey; IUGR: Intrauterine Growth Restriction; MDG: Millennium Development Goal; NMR: Neonatal Mortality Rate; SSA: Sub-Saharan Africa; WHO: World Health Organization
}

\section{Acknowledgments}

We would like to thank the measure DHS program for providing the data set.

\section{Authors' contributions}

The conception of the work, design of the work, acquisition of data, analysis, and interpretation of data was done by GAT and ZTT. Data curation, drafting the article, revising it critically for intellectual content, validation and final approval of the version to be published was done by GAT and ZTT. All authors read and approved the final manuscript.

Funding

No funding was obtained for this study.

Availability of data and materials

Data is available online and you can access it from www.measuredhs.com.

\section{Ethics approval and consent to participate}

The study doesn't involve the collection of information from subjects. Consent to participate is not applicable. Since the study is a secondary data analysis based on DHS data.

\section{Consent for publication}

Not applicable.

\section{Competing interests}

The authors declare that they have no conflict of interest.

Received: 16 April 2020 Accepted: 2 September 2020

Published online: 21 September 2020

\section{References}

1. Organization WH: Neonatal and perinatal mortality: country, regional and global estimates. 2006

2. Craglia M, Leontidou L, Nuvolati G, Schweikart J. Towards the development of quality of life indicators in the 'digital'city. Environ Planning B. 2004;31(1): 51-64.

3. Babalola S, Fatusi A. Determinants of use of maternal health services in Nigeria-looking beyond individual and household factors. BMC Pregnancy Childbirth. 2009;9(1):43.

4. Lawn JE, Rudan I, Rubens C. Four million newborn deaths: is the global research agenda evidence-based? Early Hum Dev. 2008;84(12):809-14.

5. Lawn JE, Cousens S, Zupan J, Team LNSS. 4 million neonatal deaths: when? Where? Why? Lancet. 2005;365(9462):891-900.

6. Bora JK, Saikia N. Neonatal and under-five mortality rate in Indian districts with reference to Sustainable Development Goal 3: An analysis of the National Family Health Survey of India (NFHS), 2015-2016. PLoS One. 2018; 13:7.

7. Pan K-m. Children and the millennium development goals: Progress towards a world fit for children: Unicef; 2007. 
8. Wang H, Bhutta ZA, Coates MM, Coggeshall M, Dandona L, Diallo K, Franca EB, Fraser M, Fullman N, Gething PW. Global, regional, national, and selected subnational levels of stillbirths, neonatal, infant, and under-5 mortality, 1980-2015: a systematic analysis for the global burden of disease study 2015. Lancet. 2016;388(10053):1725-74.

9. Berhan Y, Berhan A. Perinatal mortality trends in Ethiopia. Ethiop J Health Sci. 2014;24:29-40.

10. Susuman AS. Child mortality rate in Ethiopia. Iran J Public Health. 2012;41(3):9.

11. Alkema L, Chou D, Hogan D, Zhang S, Moller A-B, Gemmill A, Fat DM, Boerma T, Temmerman M, Mathers C. Global, regional, and national levels and trends in maternal mortality between 1990 and 2015, with scenariobased projections to 2030: a systematic analysis by the UN maternal mortality estimation inter-agency group. Lancet. 2016;387(10017):462-74.

12. Valdes-Dapena MA, Arey JB. The causes of neonatal mortality: an analysis of 501 autopsies on newborn infants. J Pediatr. 1970;77(3):366-75.

13. Jehan I, Harris H, Salat S, Zeb A, Mobeen N, Pasha O, McClure EM, Moore J, Wright LL, Goldenberg RL. Neonatal mortality, risk factors and causes: a prospective population-based cohort study in urban Pakistan. Bull World Health Organ. 2009;87:130-8.

14. Debelew GT, Afework MF, Yalew AW. Determinants and causes of neonatal mortality in Jimma zone, southwest Ethiopia: a multilevel analysis of prospective follow up study. PLoS One. 2014;9:9.

15. Workie NW, Ramana GN. The health extension program in Ethiopia; 2013.

16. Maes K, Closser S, Vorel E, Tesfaye Y. A women's development army: narratives of community health worker investment and empowerment in rural Ethiopia. Stud Comp Int Dev. 2015;50(4):455-78.

17. McAnarney ER. Young maternal age and adverse neonatal outcome. Am J Dis Children. 1987;141(10):1053-9.

18. Geronimus AT. The effects of race, residence, and prenatal care on the relationship of maternal age to neonatal mortality. Am J Public Health. 1986;76(12):1416-21.

19. Titaley CR, Dibley MJ, Agho K, Roberts CL, Hall J. Determinants of neonatal mortality in Indonesia. BMC Public Health. 2008;8(1):232.

20. Comstock GW, Shah F, Meyer M, Abbey H. Low birth weight and neonatal mortality rate related to maternal smoking and socioeconomic status. Am J Obstet Gynecol. 1971;111(1):53-9.

21. Samuelson JL, Buehler JW, Norris D, Sadek R. Maternal characteristics associated with place of delivery and neonatal mortality rates among verylow-birthweight infants, Georgia. Paediatr Perinat Epidemiol. 2002;16(4):305-13.

22. Swenson I. Relationships between pregnancy spacing, sex of infants, maternal age, and birth order, and neonatal and post-neonatal mortality in Bangladesh. Soc Biol. 1981;28(3-4):299-307.

23. Hobcraft JN, McDonald JW, Rutstein SO. Socioeconomic factors in infant and child mortality: a cross-national comparison. Popul Stud. 1984;38(2): 193-223.

24. Arunda M, Emmelin A, Asamoah BO. Effectiveness of antenatal care services in reducing neonatal mortality in Kenya: analysis of national survey data. Glob Health Action. 2017;10(1):1328796.

25. Rahman MM, Abidin S. Factors affecting neonatal mortality in Bangladesh. J Health Manag. 2010;12(2):137-52.

26. Singh A, Yadav A, Singh A. Utilization of postnatal care for newborns and its association with neonatal mortality in India: an analytical appraisal. BMC Pregnancy Childbirth. 2012;12(1):33.

27. Tariq P, Kundi Z. Determinants of neonatal mortality. J Pakistan Med Assoc 1999;49:56-9.

28. Cleland JG, Van Ginneken JK. Maternal education and child survival in developing countries: the search for pathways of influence. Soc Sci Med. 1988;27(12):1357-68.

29. Macro. CSAEaO. Ethiopia Demographic and Health Survey 2000. Addis Ababa, Ethiopia and Calverton, Maryland: Central Statistical Authority and ORC Macro; 2001.

30. CSACEa. I. Ethiopia Demographic and Health Survey, vol. 2016. Addis Ababa, Ethiopia, and Rockville, maryland: CSA and ICF; 2016

31. Moucheraud C, Worku A, Molla M, Finlay JE, Leaning J, Yamin AE. Consequences of maternal mortality on infant and child survival: a 25-year longitudinal analysis in Butajira Ethiopia (1987-2011). Reprod Health. 2015; 12(S1):S4.

32. ICF CSACEa. Ethiopia Demographic and Health Survey 2016. Addis Ababa, Ethiopia, and Rockville, Maryland: CSA and ICF; 2016.
33. Akinyemi JO, Bamgboye EA, Ayeni O. Trends in neonatal mortality in Nigeria and effects of bio-demographic and maternal characteristics. BMC Pediatr. 2015;15(1):36.

34. Organization WH: Every newborn: an action plan to end preventable deaths. 2014.

35. Kayode GA, Ansah E, Agyepong IA, Amoakoh-Coleman M, Grobbee DE, Klipstein-Grobusch K. Individual and community determinants of neonatal mortality in Ghana: a multilevel analysis. BMC Pregnancy Childbirth. 2014; 14(1):165.

36. Dera A, Breborowicz GH, Keith L. Twin pregnancy-physiology, complications and the mode of delivery. Arch Perinat Med. 2007;13(3):7-16.

37. Wee LY, Fisk NM. The twin-twin transfusion syndrome. In: Seminars in neonatology: 2002: Elsevier; 2002. p. 187-202

38. Kurdi AM, Mesleh RA, Al-Hakeem MM, Khashoggi TY, Khalifa HM. Multiple pregnancy and preterm labor. Saudi Med J. 2004;25(5):632-7.

39. Mekonnen Y, Tensou B, Telake DS, Degefie T, Bekele A. Neonatal mortality in Ethiopia: trends and determinants. BMC Public Health. 2013;13(1):483.

40. Bashir AO, Ibrahim GH, Bashier IA, Adam I. Neonatal mortality in Sudan: analysis of the Sudan household survey, 2010. BMC Public Health. 2013; 13(1):287.

41. Nisar YB, Dibley MJ. Determinants of neonatal mortality in Pakistan: secondary analysis of Pakistan demographic and health survey 2006-07. BMC Public Health. 2014;14(1):663.

42. Schenker MB, Samet J, Speizer F. Risk factors for childhood respiratory disease: the effect of host factors and home environmental exposures. Am Rev Respir Dis. 1983;128(6):1038-43.

43. Watson L, Boezen H, Postma D. Differences between males and females in the natural history of asthma and COPD. Eur Respir Monograph. 2003;8:5073.

44. Ezeh OK, Agho KE, Dibley MJ, Hall J, Page AN. Determinants of neonatal mortality in Nigeria: evidence from the 2008 demographic and health survey. BMC Public Health. 2014;14(1):521.

45. DaVanzo J, Hale L, Razzaque A, Rahman M. Effects of interpregnancy interval and outcome of the preceding pregnancy on pregnancy outcomes in Matlab, Bangladesh. BJOG Int J Obstet Gynaecol. 2007;114(9):1079-87.

46. Lincetto O, Mothebesoane-Anoh S, Gomez P, Munjanja S. Antenatal care. Opportunities for Africa's newborns: Practical data, policy and programmatic support for newborn care in Africa; 2006. p. 55-62.

47. Matsumura M, Gubhaju B. Women's status, household structure and the utilization of maternal health Services in Nepal: even primary-leve1 education can significantly increase the chances of a woman using maternal health care from a modem health facility. Asia-Pac Popul J. 2001 16(1):23-44.

48. Yasmin S, Osrin D, Paul E, Costello A. Neonatal mortality of low-birth-weight infants in Bangladesh. Bull World Health Organ. 2001;79:608-14.

49. Gembruch U. Prenatal diagnosis of congenital heart disease. Prenatal Diagnosis: Published in Affiliation With the International Society for Prenatal Diagnosis. 1997;17(13):1283-98.

\section{Publisher's Note}

Springer Nature remains neutral with regard to jurisdictional claims in published maps and institutional affiliations.

Ready to submit your research? Choose BMC and benefit from:

- fast, convenient online submission

- thorough peer review by experienced researchers in your field

- rapid publication on acceptance

- support for research data, including large and complex data types

- gold Open Access which fosters wider collaboration and increased citations

- maximum visibility for your research: over $100 \mathrm{M}$ website views per year

At BMC, research is always in progress.

Learn more biomedcentral.com/submissions 